\title{
Simulation of N-Butanol/Diesel Combustion and Emissions on Start of Injection
}

\author{
Jian Wu, Weiwei Shang, Bin Xu, Yibin Liu, Zhancheng Wang \\ College of Vehicle \& Transportation Engineering, Henan University of Science and Technology, \\ Luoyang 471003, China \\ 271254456@qq.com
}

\begin{abstract}
Keywords: N-butanol alcohol, fuel injection timing, numerical simulation, combustion, emissions. Abstract. This paper mainly studies the effected of fuel injection time on combustion and emissions of the four kinds of different proportions of N-butanol alcohol and diesel fuel mixed without changing the injection duration and mass under the software of FIRE. It provides the theory basis for the further development and wide application of N-butanol alcohol as an alternative fuel. Research shows that when the angle of injection advance increases, the circulation work in cylinder, temperature and pressure will increase, the accumulated heat release remain unchanged, the formation of $\mathrm{NO}_{\mathrm{X}}$ will increase, the total amount of the soot generated almost stay unchanged; when the angle of injection advance decreases, the circulation work, the temperature and pressure in cylinder can be reduced, the accumulated heat release decrease slightly, the formation of $\mathrm{NO}_{\mathrm{X}}$ decreased significantly, the generation of soot increases slightly. Under the same injection time, with the increase of N-butanol alcohol in the mixed fuel ratio, pressure and temperature in cylinder rise, the accumulated heat release basically remains unchanged; total $\mathrm{NO}_{\mathrm{X}}$ formation increases after decreased first, the amount of total soot formation shows a trend of decrease.
\end{abstract}

\section{Introduction}

The start of injection of engine combustion and emissions performance has a direct and important influence; it also determines the performance and emissions of engine [1]. The shortage of oil resources and the deterioration of the global environment has become two big problem in today's social, for the long-term sustainability of the global development, looking for a clean alternative fuel has become an important direction of internal combustion engine research. Alcohol fuel instead of the traditional fossil fuels is thought to be a solution to the energy crisis and environmental pollution. $\mathrm{N}$-butanol, as the representative of the second generation substitute fuel, is considered to be zero carbon smoke emission, and can effectively reduce $\mathrm{NO}_{\mathrm{X}}$ and $\mathrm{PM}$ emissions [2]; and N-butyl alcohol containing oxygen, while ensuring the power performance and fuel economy of diesel engine at the same time, and effectively reduce $\mathrm{NO}_{\mathrm{X}}$ and $\mathrm{PM}$ emissions, and don't need to make big changes to the established structure of internal combustion engine [3].

Numerical simulation overcome the negative impact of the test, the experimental research, theoretical analysis and scientific computing organically integrated, thus reducing the time and cost savings, has become a diesel engine research and design of a kind of effective means [4]. In this paper, on the basis of experiment, establishment of reliable model of diesel engine combustion chamber in a fixed mode of N-butyl alcohol and diesel fuel mix combustion were studied in different injection time, exploring ways through modification to improve the combustion performance of diesel engine fuel, realize partly replace diesel oil, to improve the performance of $\mathrm{N}$-butanol diesel engines and $\mathrm{N}$-butyl alcohol and diesel fuel mixed is widely support.

\section{Calculation Model and Calculation Conditions}

Calculation Model and verification. The engine used in this paper was a turbocharged intercooled and electronically controlled high pressure common rail diesel engine. The parameters are shown in Table 1. 
Table 1 Parameters of Diesel Engine

\begin{tabular}{cc}
\hline Items & Value \\
\hline Bore $(\mathrm{mm})$ & 83.1 \\
Stroke(mm) & 92 \\
Length(mm) & 142.5 \\
Compress ratio & 16.7 \\
Displacement(L) & 1.996 \\
Nozzle hole & 7 \\
Radius of nozzle Hole $(\mathrm{mm})$ & 0.133 \\
\hline
\end{tabular}

In this article, we assume that the cylinder temperature and gas distribution are uniform and symmetrical. According the number of nozzle is 7 , the combustion chamber can be divided into seven parts, and one seventh needs to be calculated, which can greatly simplify mesh and shorten computation time[5,6,7]. At the top dead center on grid model is shown in Fig. 1, and the number of grid is 2607.

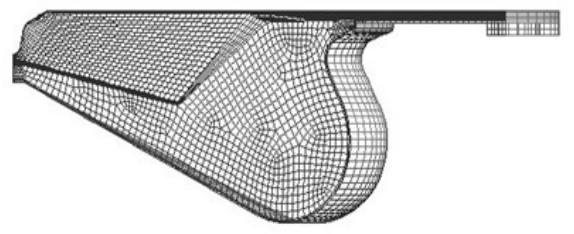

Fig. 1 Grid Model of Chamber

The calculation starts at inlet valve closure and stops at outlet valve opened. At the initial moment, the pressure is $323688 \mathrm{~Pa}$, the temperature is $401 \mathrm{~K}$. The mass of fuel injections will use experiment value, and the fuel injection rate was simplified. Pilot injection was simplified to an isosceles triangle, and main injection was simplified isosceles trapezoid. Initial boundary temperature used AVL recommended value $[5,6]$. In the model the physical and chemical process is shown as Table 2 .

Table 2 Calculation model

\begin{tabular}{cc}
\hline Model & Name \\
\hline Spray model & WAVE \\
Combustion model & EBU \\
Ignition model & Diesel_MIL \\
Turbulent equation & k-zeta-f \\
NO $_{\mathrm{X}}$ model & Extended Zeldovich \\
Soot model & K/H/M \\
Particles interact with wall model & Walljet1 \\
\hline
\end{tabular}

Fig. 2 and Fig. 3 are indicator diagrams of experiment and simulation results respectively using diesel and 5\%(volume of N-butanol)N-butanol/Diesel fuel mixture. It can be seen that the indicator diagrams are consistent generally. In general, the errors are within 5\%. So the calculation model is reasonable and correct, which can be used for combustion simulation of fuel mixture.

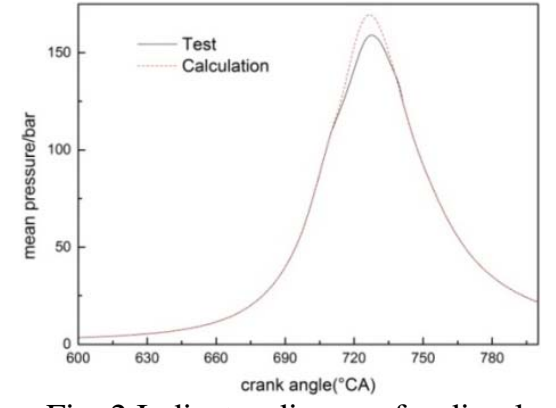

Fig. 2 Indicator diagram for diesel

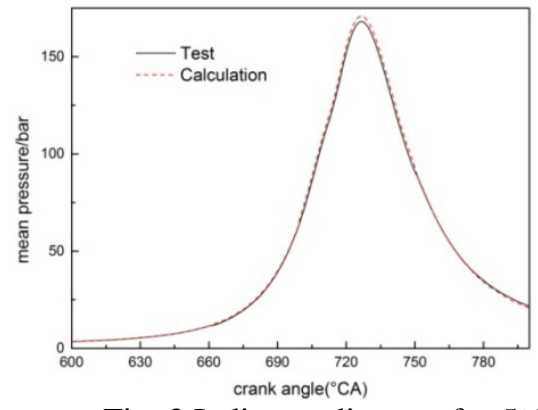

Fig. 3 Indicator diagram for 5\% mixture

Calculation Conditions. This paper defines when injection in advance to "+", when the injection delay for "-".Injection timing moment ( $9{ }^{\circ}$ CA BTDC) to 0 , on the basis of injection timing, the condition was calculated at $3000 \mathrm{r} / \mathrm{min}, 300 \mathrm{~N} \cdot \mathrm{m}$ of the influence of the mixed fuel combustion and emission characteristics, and injection time are $+6^{\circ} \mathrm{CA},+3^{\circ} \mathrm{CA},-3^{\circ} \mathrm{CA}$ and $-6^{\circ} \mathrm{CA}$, and n-butanol alcohol mass fraction is $10 \%, 20 \%, 30 \%$ and $20 \%$.

\section{Results and Analysis}

Economic Analysis. Table 3 gives the indicated specific fuel consumption contrast of four types of fuel in different start of injection. The ISFC in Table 3 is reduced fuel consumption which is 
converted into the same energy fuel consumption of diesel fuel consumption rate for the mixed fuel of instructions. From the table, the ISFC increases as the injection time delays. This is due to the injection delay reduces the amount of work. Only from the perspective of the economics, injection in advance is helpful to improve the mixed fuel economy. In addition, keep the start of injection unchanged, the more N-butanol alcohol in the mixed fuel, the higher of fuel consumption rate. It is related to the mixed fuel calorific value. $\mathrm{N}$-butanol calorific value is relatively low, the greater the proportion of mixed fuel of N-butanol, the lower calorific value of the mixed fuel, so the engine must burn more fuel to achieve the same power.

Table 3 Comparison of ISFC for Different Spray Angle

\begin{tabular}{cccccc}
\hline Items & $+\mathbf{6}^{\circ} \mathbf{C A}$ & $+3^{\circ} \mathbf{C A}$ & $\mathbf{0}$ & $-3^{\circ} \mathbf{C A}$ & $\mathbf{- 6}^{\circ} \mathbf{C A}$ \\
\hline NB10 & $235.1 \mathrm{~g} / \mathrm{kWh}$ & $239.7 \mathrm{~g} / \mathrm{kWh}$ & $245.8 \mathrm{~g} / \mathrm{kWh}$ & $254.9 \mathrm{~g} / \mathrm{kWh}$ & $265.6 \mathrm{~g} / \mathrm{kWh}$ \\
NB20 & $257.9 \mathrm{~g} / \mathrm{kWh}$ & $261.9 \mathrm{~g} / \mathrm{kWh}$ & $267.8 \mathrm{~g} / \mathrm{kWh}$ & $291.1 \mathrm{~g} / \mathrm{kWh}$ & $305.8 \mathrm{~g} / \mathrm{kWh}$ \\
NB30 & $293.1 \mathrm{~g} / \mathrm{kWh}$ & $296.6 \mathrm{~g} / \mathrm{kWh}$ & $300.7 \mathrm{~g} / \mathrm{kWh}$ & $308.0 \mathrm{~g} / \mathrm{kWh}$ & $317.3 \mathrm{~g} / \mathrm{kWh}$ \\
NB50 & $420.9 \mathrm{~g} / \mathrm{kWh}$ & $422.5 \mathrm{~g} / \mathrm{kWh}$ & $427.0 \mathrm{~g} / \mathrm{kWh}$ & $434.1 \mathrm{~g} / \mathrm{kWh}$ & $444.1 \mathrm{~g} / \mathrm{kWh}$ \\
\hline
\end{tabular}

Combustion characteristic. Fig. 4 shows the IMPE contrast of four fuels under different injection time. As the start of injection in advance, the IMPE increases, and the maximum pressure rises, the amount of work per cycle to increases. This is mainly due to the start of injection advance, ignition delay period extends accordingly, ignition delay period, increase in the number of combustible mixture formation, premixed combustion increase lead to the maximum explosion pressure in cylinder, and the IMPE increases. It also can be seen from the picture, when the injection time is consistent, IMPE increases with N-butanol proportion in the mixed fuel on the rise. This is because the fuel injection mass increases with increasing proportion of N-butanol, and injection time remain the same, and results to the injection rate increase; the fuel in cylinder injection mass increases at the same time (equivalent fuel quantity increases), combustion heat quantity increasing leads to rising pressure.

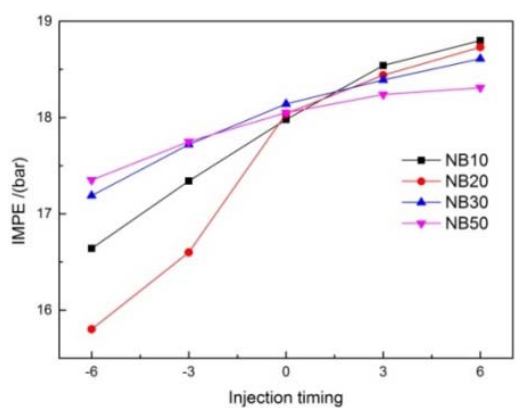

Fig. 4 Contrast of IMPE for Different Spray Angle

Fig. 5 for accumulated heat release contrast of three different ratios mixed fuel. Can be seen from the diagram, fuel injection time delay didn't affect the amount of accumulated heat release. This is mainly because there are moments change affects the allocation proportion of premixed combustion and diffusive combustion, and no affect the accumulated heat release.
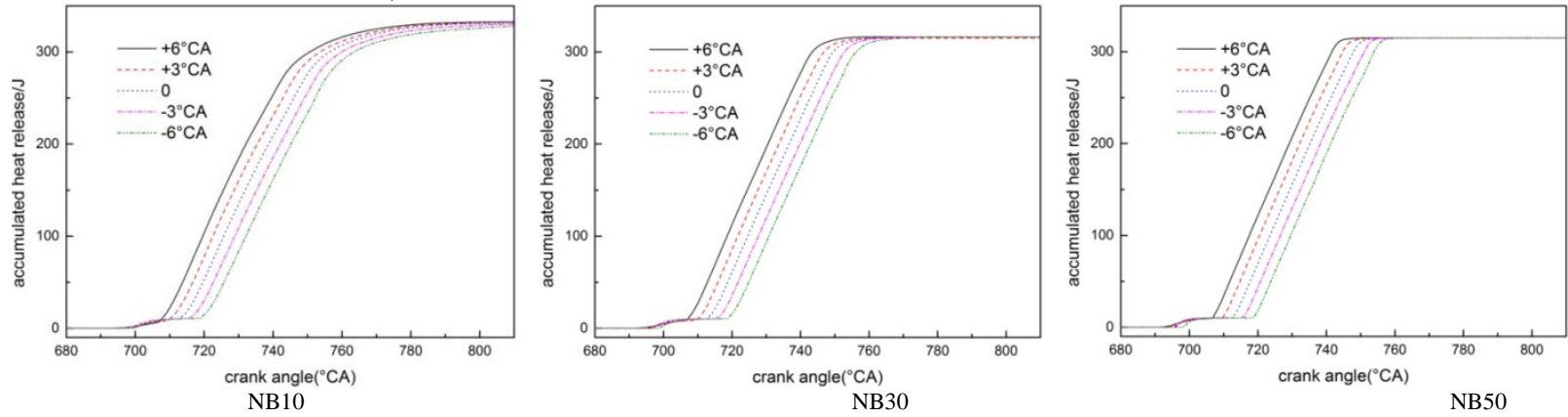

Fig. 5 Contrast of Accumulated Heat Release for Different Spray Angle

Table 4 is the contrast of maximum combustion temperature and the crank angle of maximum combustion temperature. Can be seen from the table, as the start of injection delay, the maximum combustion temperature is decline, and the crank angle delay. This is due to the injection delay makes combustion center also postpone back, more and more fuel combustion on the power stroke, the 
piston downward, with the decrease of the maximum temperature. Also can be seen from the table, keep the start of injection constant, as N-butanol mixture ratio increases, the maximum combustion temperature first increases then decreases. This is because the fuel injection mass increases and the amount of combustion heat quantity increased; the proportion of N-butyl alcohol increases to 50\%, the highest temperature is decreased. This is because the latent heat of vaporization of N-butyl alcohol is big in NB50 fuel, which lead to more heat to atomization absorption, and the highest average combustion temperature decreases [8].

Table 4 Comparison of Temperature for Different Spray Angle

\begin{tabular}{|c|c|c|c|c|c|c|c|c|c|c|}
\hline \multirow{2}{*}{ Items } & \multicolumn{2}{|c|}{+6} & \multicolumn{2}{|c|}{+3} & \multicolumn{2}{|r|}{0} & \multicolumn{2}{|r|}{-3} & \multicolumn{2}{|c|}{-6} \\
\hline & $T / K$ & Angle $/{ }^{\circ} \mathrm{CA}$ & $T / K$ & Angle $/{ }^{\circ} \mathrm{CA}$ & $T / K$ & Angle $/{ }^{\circ} \mathrm{CA}$ & $T / K$ & Angle $/{ }^{\circ} \mathrm{CA}$ & $T / K$ & Angle $/{ }^{\circ} \mathrm{CA}$ \\
\hline NB10 & 1949.8 & 744.8 & 1904.7 & 748.6 & 1875.7 & 753 & 1846.8 & 756 & 1819.6 & 759 \\
\hline NB20 & 1994.8 & 744.4 & 1948.6 & 747.8 & 1912.4 & 751 & 1797.7 & 754 & 1765.8 & 757 \\
\hline NB30 & 2018.3 & 743.4 & 1970.1 & 746.8 & 1940.3 & 749.8 & 1907.3 & 753.5 & 1873.4 & 756.5 \\
\hline NB50 & 1994.3 & 742.6 & 1946.8 & 745.8 & 1904.2 & 748.8 & 1874.2 & 752.5 & 1850.3 & 755.5 \\
\hline
\end{tabular}

Emission Performance. Fig. 6 indicates $\mathrm{NO}_{\mathrm{X}}$ formation mass fraction in different injection time with four mixed fuel. The condition of $\mathrm{NO}_{\mathrm{X}}$ formation is high temperature, oxygen enrichment and the duration time in high temperature [9]. It can be seen clearly from Fig. 6, as the start of injection delays, $\mathrm{NO}_{\mathrm{X}}$ emissions significantly reduces. This is mainly because injection delay results to the decrease of temperature in cylinder. When keeping the start of injection constant, the cylinder temperature rising for NB10, NB20 and NB30, oxygen content is also on the rise in the mixed fuel, and this causes the $\mathrm{NO}_{\mathrm{X}}$ generation increase; Compared with NB30, NB50 combustion temperature is reduced, and it will inhibit the formation of $\mathrm{NO}_{\mathrm{X}}$. In addition, the start of injection delay increases total $\mathrm{NO}_{\mathrm{X}}$ formation obviously, this is because when the injection delays, ignition delay shortens, and it is not good for the combination of fuel and air; the inhomogeneous distribution of oxygen in cylinder promotes the formation of $\mathrm{NO}_{\mathrm{X}}$.

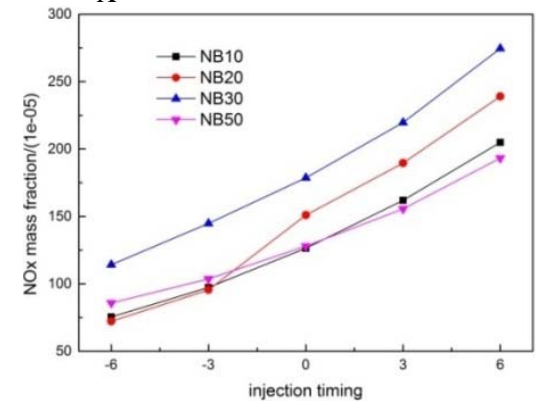

Fig. 6 Contrast of $\mathrm{NO}_{\mathrm{X}}$ for Different Spray Angle

Fig. 7 shows three different proportions of mixed fuel soot formation mass fraction in different injection time. It can be seen from the diagram, for each proportion of mixed fuel, as the injection delays, the generation of soot volume increases slightly, but the increase is not much. This is mainly because the injection delay leads to a loss of combustion temperature in cylinder, promoting the formation of Soot, and is not helpful to the soot oxidation in the later combustion, because the final emission of soot is the result of competing with the formation and oxidation process [10]. In addition, it also can be seen from the figure that by increasing the proportion of n-butanol alcohol, we can effectively reduce Soot emissions. This is mainly because of the
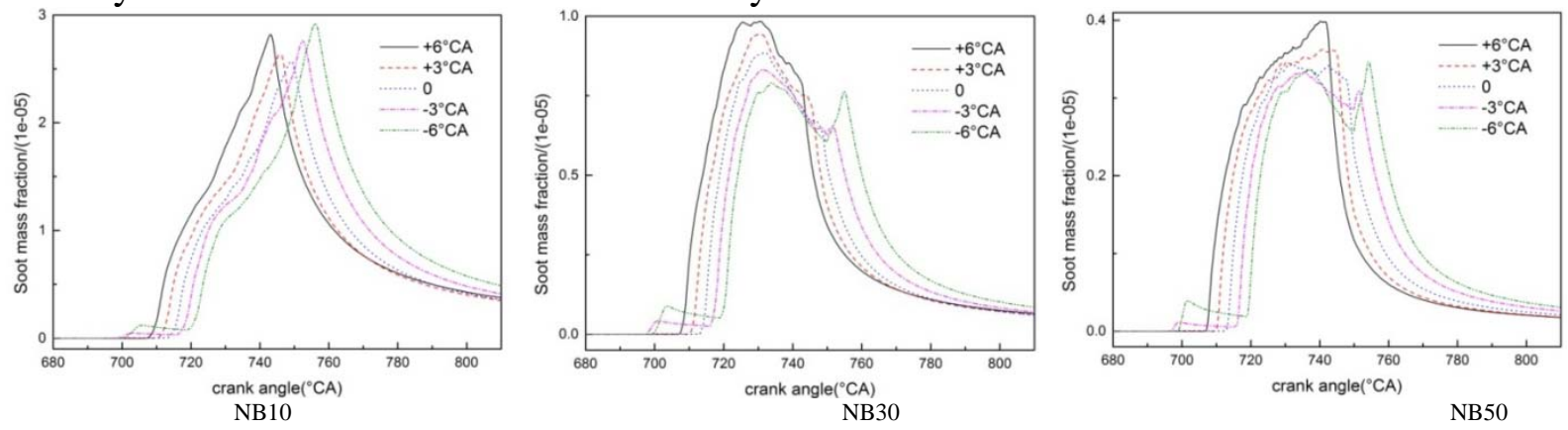

Fig. 7 Contrast of Soot for Different Spray Angle 
oxygen in the N-butanol alcohol; it increases the oxygen concentration in the mixture, accelerates the soot oxidation, and reduces soot emissions. Changes the start of injection for the same fuel has little influence on the generation of soot.

\section{Conclusions}

As the start of injection delays, the pressure and temperature of each fuel increases as well as work of each cycle, and the maximum pressure rises. When keeping the start of injection constant, with the increase of N-butanol proportion in the mixed fuel, the pressure and temperature in cylinder and the work decrease, and the maximum pressure also decreases. For the same kind of fuel with the start of injection delay, the fuel consumption increases. When keeping the start of injection constant, with the increase of N-butanol proportion in the mixed fuel, fuel consumption rate is increasing. As the start of injection delays, the formation of $\mathrm{NO}_{\mathrm{X}}$ reduction, soot generation is also reduced. When keeping the start of injection constant, with the increase of N-butanol proportion in mixed fuel, the formation of $\mathrm{NO}_{\mathrm{X}}$ first increase then decreases, and Soot generation decreases.

\section{References}

[1] Longbao Zhou, Study the internal combustion engine, Beijing: Mechanical industry press, 2012. (In Chinese)

[2] Xianjun Zeng, Jian Deng, Research Progress of Butanol as an Alternative Vehicle Fuel, J. Small Internal Combustion Engine and Motorcycle, 2012, 41(1): 76-80.

[3] Quanchang Zhang, Mingfa Yao, Zunqing Zheng, Effects of N-Butanol on Combustion and Emissions of Low Temperature Combustion, J. Journal of Combustion Science and Technology, 2010, 16(4): 363-368.

[4] Xiqiang Zhang, Jipeng Zhang, Yulei Zhao, Simulative Calculation of the Combustion Process for a 6P125ZQ Diesel Engine in the Rated Power, J. Internal Combustion Engine \& Parts, 2011(9): 9-14.

[5] AVL, CFD-Solver_v2010_04_ICE-Physics-Chemistry, 2010:75-93.

[6] S.V. Sheikh, N. P. Goknale. Piston Cavity Optimization for DI Diesel Engine using ESE Diesel, Annual meeting papers of AVL, 2010.

[7] Kong S C, Reitz R D. Application of detailed chemistry and CFD for predicting direct injection HCCI engine combustion and emissions, J. Proceedings of the Combustion Institute. 2002, (29): 663-669.

[8] Peng Deng, Yingjie Ma, Huang Ronghua, Study of the Alcohol diesel surface tension with composition and temperature, The Chinese society of internal combustion engine combustion energy-saving purification section, Nanning: The Chinese society of internal combustion engine, 2012.

[9] Jinke Gong, Auto emissions and control technology, Beijing: China Communications Press, 2012. (In Chinese).

[10]Deming Jiang, The internal combustion engine combustion and emissions,” Xi'an: Xi'an Jiaotong University Press, 2001. (In Chinese) 